\title{
Impact of castration with or without alpha-tocopherol supplementation on the urethral sphincter of rats
}

\author{
Mirian Kracochansky, Leonardo Oliveira Reis, Fabio Lorenzetti, Valdemar Ortiz, Miriam Dambros
}

Division of Geriatric Urology, Escola Paulista de Medicina, Universidade Federal de Sao Paulo (MK, FL, VO, MD), Sao Paulo, Brazil and Division of Urology, School of Medical Sciences, University of Campinas, Unicamp (LOR), Sao Paulo, Brazil

\section{ABSTRACT}

Objective: To analyze the impact of low levels of testosterone induced by orchiectomy and the effect of alpha-tocopherol supplementation on oxidative stress in the urethral sphincter.

Materials and Methods: Forty male Wistar rats weighing 250-300g were divided into four groups with 10 each: Sham group; Orchiectomy group: bilateral orchiectomy; Orchiectomy-pre-Tocopherol group: bilateral orchiectomy preceded by alpha-tocopherol supplementation for four weeks; Orchiectomy-full-Tocopherol group: bilateral orchiectomy with alpha-tocopherol supplementation for four weeks preceding the procedure and for eight weeks afterwards. At the protocol end, animals were euthanized and had the sphincter analyzed stereologically focusing on collagen and muscle fibers percentage. Oxidative stress levels were determined using 8-epi-PGF2.

Results: The 8-epi-PGF2 levels were statistically higher $(\mathrm{p}<0.0003)$ in the 0rchiectomy group compared to others groups while Sham and Orchiectomy-fullTocopherol groups presented statistically similar values $(\mathrm{p}=0.52)$. Collagen volumetric densities were significantly lower in Sham and Orchiectomy-full-Tocopherol groups $(\mathrm{p}<0.022)$. Sham group presented statistically greater muscle fiber percent.

Conclusion: Castration caused oxidative stress in the urethral sphincter complex, with increased collagen deposition. Alpha-tocopherol had a protective effect and its supplementation for twelve weeks provided the greatest protection.

\section{ARTICLE INFO}

\section{Key words:}

apoptosis; alpha-tocopherol; oxidative stress; antioxidants;

castration

Int Braz J Urol. 2012; 38: 277-83

Submitted for publication:

May 20, 2011

Accepted after revision:

October 18, 2011

\section{INTRODUCTION}

The urethral sphincter complex is subject to degeneration in the same way as muscles are. While little is known about the physiopathological basis of sphincter dysfunction at the molecular level (1), urinary incontinence physiopathology is frequently described in terms of the damage that occurs at the cell and/or tissue level. Experi- mental studies on the levator ani muscle in rats have shown that orchiectomy leads to incapacity of the satellite cells to respond mitotically, with consequent muscle atrophy (2).

The skeletal musculature diminishes with age by means of reduction in the number of muscle fibers and atrophy among the remaining fibers, through mechanisms that have still not been completely identified $(3,1)$. Among the 
mechanisms responsible for such atrophy are proteolytic routes and neurological and hormonal changes, such as decrease in the serum levels of growth hormone and testosterone (4-6).

Diabetic animals presented reductions in sphincter pressures associated with increased oxidative stress on the anal sphincter musculature, with a return to normality after administering an antioxidant agent (7).

The present study evaluated the changes on the urethral sphincter apparatus resulting from low levels of sexual hormones and the action of alpha-tocopherol supplementation on the oxidative stress induced by orchiectomy.

\section{MATERIALS AND METHODS}

Forty male Wistar rats of reproductive age (three months old), weighing 250-300g were kept in a controlled environment $\left(25 \pm 2{ }^{\circ} \mathrm{C}\right)$ with exposure to light for 12 hours a day, water available ad libitum and Labina ${ }^{\circledR}$ animal chow (Purina ${ }^{\circledR}$ ).

The study was done according to the guidelines of the Brazilian College for Animal Experimentation (COBEA) under approval of the Institutional Committee for Ethics in Animal Research.

Groups (10 animals each one) were formed as follows: Sham group - underwent opening and closing the scrotal sac; Orchiectomy group - underwent bilateral orchiectomy; Orchiectomy-pre-Tocopherol group - underwent bilateral orchiectomy preceded by alpha-tocopherol supplementation for four weeks; Orchiectomyfull-Tocopherol group - underwent bilateral orchiectomy with alpha-tocopherol supplementation for four weeks preceding the procedure and for eight weeks afterwards.

Alpha-tocopherol was administered dissolved in $0.1 \mathrm{~mL}$ of sesame oil (Galênica, SP) at a dosage of $1000 \mathrm{UI} / \mathrm{kg} /$ week intramuscularly into the animal's dorsum using a fine insulintype needle.

At the end of the protocol, all the animals were anesthetized by means of ether inhalation, and venous blood was collected from the dorsal vein of the tail, in order to assay the 8-epi-
PGF2 and testosterone levels. They were then euthanized trough pneumotorax and $\mathrm{CO}_{2}$ narcosis and resection of the urethral sphincter was performed. The blood samples were stored at $-80{ }^{\circ} \mathrm{C}$ until analysis, using tubes containing $0.5 \mathrm{~g} / \mathrm{L}$ of butyrated hydroxytoluene as a free radical chelating agent.

Alpha-tocopherol was quantified by means of high-performance chromatography in tissue, using fluorescence with an excitation wavelength of $292 \mathrm{~nm}$ and an emission wavelength of $340 \mathrm{~nm}$. The values were expressed in $\mathrm{ng} / \mathrm{mg}$ of tissue.

Total serum testosterone was assayed by means of competitive radioimmunoassaying (testosterone direct radioimmunoassay kit, Immunotech, Brazil; cat \# 1119).

The concentration of 8-epi-PGF2 was measured using a commercial enzymatic immunoassaying kit (Cayman Chemical, USA). The 8-epi-PGF2 conjugated with antibody was detected by means of a reaction with 5.5-dithiobis (2-nitrobenzoic acid)-DTNB (absorbed at 405 $\mathrm{nm}$ ), which was hydrolyzed by the acetylcholinesterase of the conjugate. The detection limits were 6 to $500 \mathrm{pg} / \mathrm{mL}$.

Stereology was the method chosen for morphometrically evaluating the muscle and collagen fibers of the urethral sphincter. The fiber analysis was performed using preparations from seven-micrometer thin sections (8).

The modified picrosirius red staining technique was used. The slides were analyzed via optical microscopy at a magnification of 40x. Ten fields per slide and ten slides per animal were evaluated. The volumetric density of the collagen fibers and muscle fibers was analyzed by overlaying the M-42 grid system on the computed morphological image of the slides. The volumetric density is the relative density taken up by fibers in the tissue under examination. The stereological method quantitatively determines the parameters of the anatomical structural base on the two-dimensional thin sections, in three dimensions (9).

The data obtained were analyzed using the SPSS 12.0 statistics software (SPSS Inc., USA) and were expressed as means \pm standard 
deviation. To validate the results, analysis of variance (multivariate analysis) and the nonparametric Newman-Keuls test for multiple comparisons and the nonparametric Kruskal-Wallis test, with the Bonferroni correction test were used to assess the differences between the independent samples. The criterion for significance was taken to be two-sided $\mathrm{p}<0.05$.

\section{RESULTS}

The alpha-tocopherol concentrations were $0.61 \mathrm{ng} / \mathrm{mg}$ of body weight in Sham group; $0.69 \mathrm{ng} / \mathrm{mg}$ in Orchiectomy group; $1.73 \mathrm{ng} / \mathrm{mg}$ in Orchiectomy-pre-Tocopherol group; and $1.83 \mathrm{ng} /$ $\mathrm{mg}$ in Orchiectomy-full-Tocopherol group. The comparative analysis showed that the values in both tocopherol-supplemented groups were statistically greater $(\mathrm{p}<0.05)$.

The serum testosterone concentrations immediately before sacrifice in the orchiectomized groups with and without alpha-tocopherol replacement were less than $20 \mathrm{pg} / \mathrm{mL}$ (sensitivity limit for the method applied). This demonstrated that there was a significant hormone deficit at the time of sacrificing these animals, except for Sham group.

Analysis of the 8-epi-PGF2 levels demonstrated statistically higher values $(p<0.0003)$ in Orchiectomy group $(5.1 \mathrm{pg} / \mathrm{mL})$, in relation to Sham group $(2.3 \mathrm{pg} / \mathrm{mL})$, Orchiectomy-preTocopherol group $(2.4 \mathrm{pg} / \mathrm{mL})$ and Orchiectomyfull-Tocopherol group $(2.6 \mathrm{pg} / \mathrm{mL})$.

Figure- 1 shows picrosirius stained external urethral sphincter highlighting collagen fibers distributed among muscle fibers.

Table-1 and Figure-2 demonstrate the volumetric density of the collagen fibers in the external urethral sphincter, in the four studied groups. It was observed that Sham and Orchiectomy-full-Tocopherol groups presented statistically similar values $(p=0.52)$. Orchiectomy and Orchiectomy-pre-Tocopherol groups presented volumetric densities that were greater than those of Sham and Orchiectomy-full-Tocopherol groups ( $\mathrm{p}<0.022)$. When analyzing Orchiectomy and Orchiectomy-pre-Tocopherol groups, it was also observed that the first presented a greater volumetric concentration of collagen fibers compared to the second $(\mathrm{p}=0.024)$.

Figure 1 - Picrosirius stained external urethral sphincter. Arrows showing collagen fibers distributed between muscle fibers (40X). A: Sham group; B: Orchiectomy group; C: Orchiectomy-pre-Tocopherol group; D: Orchiectomy-full-Tocopherol group.

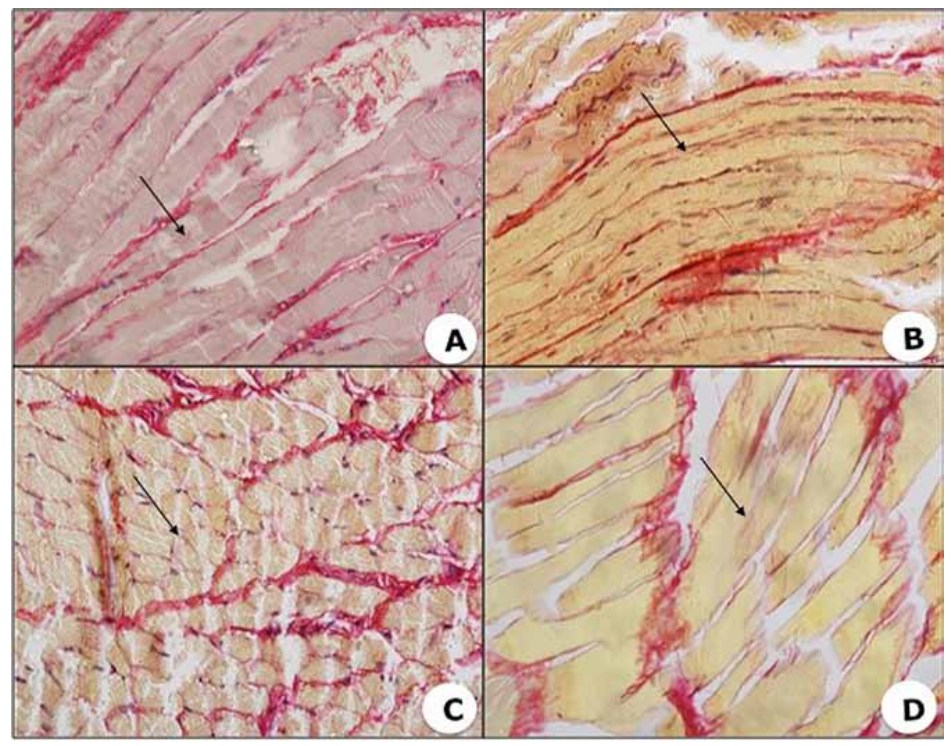


Table 1 - Descriptive analysis on collagen fibers of the external urethral sphincter.

\begin{tabular}{lcccc}
\hline \multicolumn{5}{c}{ Volumetric density of the collagen fibers of the external urinary sphincter of male rats $(\mathrm{Vv})$ - \% } \\
\hline Values & Sham & Orchiectomy & $\begin{array}{c}\text { Orchiectomy-pre- } \\
\text { Tocopherol }\end{array}$ & $\begin{array}{c}\text { Orchiectomy-full- } \\
\text { Tocopherol }\end{array}$ \\
\hline Minimum & 9.05 & $\mathbf{2 9 . 3 2}$ & 17.85 & 9.29 \\
25th percentile & 10.35 & $\mathbf{3 1 . 9 8}$ & 20.22 & 11.60 \\
Median & 11.34 & $\mathbf{3 1 . 9 8}$ & 20.22 & 11.60 \\
75 th percentile & 12.85 & $\mathbf{3 6 . 3 2}$ & 24.19 & 14.98 \\
Maximum & 13.10 & $\mathbf{3 9 . 1 0}$ & 26.52 & 16.52 \\
Standard error & 0.50 & $\mathbf{1 . 5 7}$ & 1.85 & 0.88 \\
Mean (SD) & $11.70( \pm 1.43)$ & $\mathbf{3 4 . 2 1}( \pm \mathbf{4 . 3})$ & $21.12( \pm 4.00)$ & $12.23( \pm 1.8)$ \\
$95 \%$ Cl & $10.42-12.70$ & $\mathbf{3 0 . 0 8 - 3 8 . 5 1}$ & $18.34-25.60$ & $10.65-14.01$ \\
\hline
\end{tabular}

SD - standard deviation; $\mathbf{C l}$ - confidence interval; $\mathbf{N}=10$ in each group

Table-2 and Figure-3 demonstrate the volumetric density of the muscle fibers in the four groups. It can be observed that Sham group presented values that were statistically greater than those in the other groups $(\mathrm{p}=0.028)$.

Figure 2 - External urethral sphincter collagen fibers density $(n=10$ per group; different lowercase letters indicate statistically significant differences between the groups, $p<0.05$ ). A: Sham group; B: Orchiectomy group; C: Orchiectomy-pre-Tocopherol group; D: Orchiectomy-full-Tocopherol group.

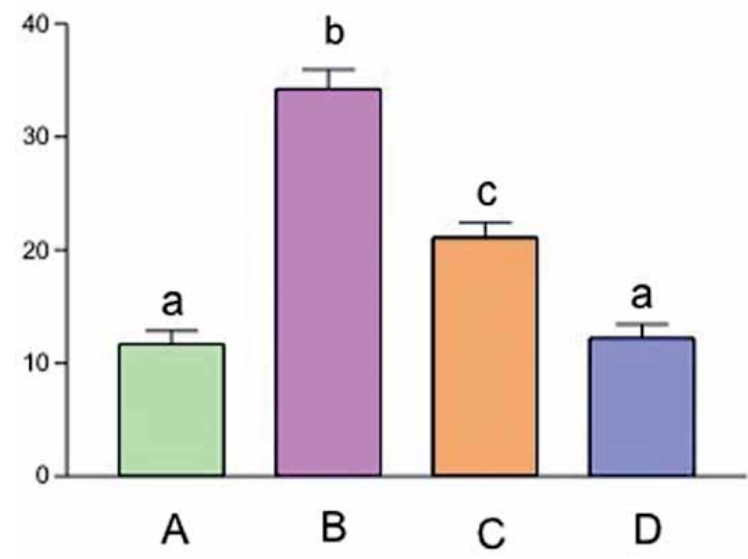

\section{DISCUSSION}

The process of aging and concurrent hormone decline is responsible for the decrease of the percent of muscle fibers of the rhabdosphincter, which are closely related to urinary sphincter culminating in urinary dysfunction (10-12). Urodynamic evaluation has demonstrated decreased maximum urethral pressure, urethral closing pressure and sphincter length in elderly men, compared with younger controls (10).

This study showed increased collagen fiber density in the animals with higher rates of oxidative stress. The animals in Orchiectomy and Orchiectomy-pre-tocopherol groups presented greater volumetric density for collagen fibers than Sham and Orchiectomy-full-tocopherol groups, ( $p<0.022)$. Thus, it can be noted that alpha-tocopherol had a protective effect and avoided higher rates of oxidative stress, thereby resulting in lower deposition of collagen fibers in the sphincter tissue.

Comparing Orchiectomy and Orchiectomy-pre-tocopherol groups, a statistically significant difference in the volumetric density of 
Table 2 - Descriptive analysis on muscle fibers of the external urethral sphincter.

\begin{tabular}{|c|c|c|c|c|}
\hline \multicolumn{5}{|c|}{ Volumetric density of the muscle fibers of the external urinary sphincter of male rats (Vv) - \% } \\
\hline Values & Sham & Orchiectomy & $\begin{array}{c}\text { Orchiectomy-pre- } \\
\text { Tocopherol }\end{array}$ & $\begin{array}{l}\text { Orchiectomy-full- } \\
\text { Tocopherol }\end{array}$ \\
\hline Minimum & 83.48 & 59.20 & 67.86 & 65.28 \\
\hline 25th percentile & 84.22 & 61.48 & 68.21 & 67.92 \\
\hline Median & 87.76 & 64.25 & 73.11 & 67.10 \\
\hline 75th percentile & 89.10 & 68.07 & 76.53 & 69.81 \\
\hline Maximum & 91.05 & 71.89 & 79.16 & 71.00 \\
\hline Standard error & 1.38 & 1.96 & 1.95 & 1.52 \\
\hline Mean (SD) & $88.3( \pm 2.87)$ & $65.79( \pm 5.88)$ & $73.88( \pm 5.85)$ & $68.77( \pm 2.50)$ \\
\hline $95 \% \mathrm{Cl}$ & $85.14-90.17$ & $60.14-70.92$ & $68.50-78.49$ & $66.15-70.15$ \\
\hline
\end{tabular}

SD - standard deviation; $\mathbf{C l}$ - confidence interval; $\mathbf{N}=10$ in each group

the collagen fibers was found $(p<0.05)$, from which it could be commented that supplementation with alpha-tocopherol before the orchiectomy procedure led to partially decreased effects on the collagen fibers.

Figure 3 - External urethral sphincter muscle fibers density ( $\mathrm{n}=10$ per group; * $\mathrm{p}<0.05$ compared to the other groups). A: Sham group; B: Orchiectomy group; C: Orchiectomy-pre-Tocopherol group; D: Orchiectomy-full-Tocopherol group.

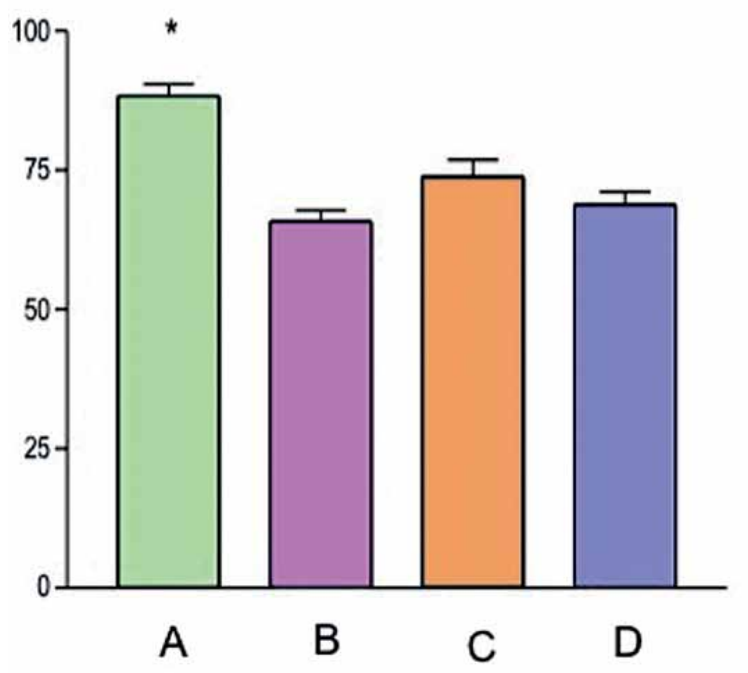

The animals in Sham group presented greater volumetric density of muscle fibers than other groups, thus allowing the hypothesis that castration led to decreased numbers of muscle fibers in the urethral sphincter complex and that supplementation with alpha-tocopherol was not effective for inhibiting the process.

The presence of notable decrease in the number of striated muscle cells in the urethral sphincter of elderly people have been reported due to apoptosis, possibly related to urinary dysfunction $(12,13)$.

With decreasing volume of the striated sphincter musculature and blood vessels, increasing collagen deposition was found to occur in the region of the external urethral sphincter related to aging (14).

The presence of androgen receptors in motor neurons of the pudendum nerve that controlled the urethral sphincter of rats has been reported, thus suggesting that androgens have an influence on urinary continence control (11).

Orchiectomy in rats was found to increase lipid peroxidation in muscle tissue while, interestingly, testosterone supplementation in such 
rats promoted reversal of this lipid peroxidation in the tissue $(14,15)$.

There is a report in the literature showing protection against aging with the use of alphatocopherol in Sprague-Dawley rats (16). In that study, assaying for 8-epi-PGF2 was used to prove the presence of oxidative stress eight weeks after bilateral orchiectomy, since this is a marker for oxidative stress. This has been used in both animals and humans $(17,18)$.

Antioxidant agents are capable of limiting or preventing the harmful effects of these radicals, although these protective mechanisms diminish during the process of aging $(18,19)$.

Antioxidants have been demonstrated to be effective defenders from the well-known free radicals damage in a wide range of situations; in urology from those causing infertility to the systemic effect of antineoplastic drugs (20). Alphatocopherol is one of the most powerful and effective exogenous antioxidants, since it prevents peroxidation and avoids the effects of oxidative stress (21-23). We decided to use alpha-tocopherol because its pharmacokinetics have been well established, which helped determinethe dose to be used in its oral or parenteral presentation (21).

Increased levels of 8-epi-PGF2 in cells of the urethral sphincter complex in rats subjected to orchiectomy without alpha-tocopherol replacement have been demonstrated in the present study, thereby translating in an increase in oxidative stress associated with hypoandrogenism. This difference was statistically significant when compared with the Sham group and the groups with alpha-tocopherol supplementation.

This study revisited the protective effect of alpha-tocopherol in reducing the oxidative stress levels and expanded its possible application to the level of the urethral sphincter complex, based on several previous studies that demonstrated the alpha-tocopherol beneficial action in relation to different urological diseases (23-25).

Nonetheless, further studies will be needed in order to achieve a better explanation for the influence of alpha-tocopherol on the concentration of sphincter collagen fibers.

Oxidative stress plays a considerable part in the degenerative process in the urethral sphincter complex consequent to low testosterone levels. It was observed that supplementation with alpha-tocopherol following bilateral orchiectomy decreased the intensity of this process. It is suggested that low testosterone levels are associated with induction of free radical formation. These would at least partially be responsible for the degeneration of the sphincter muscle fibers through collagen fiber deposition.

Together with this hypothesis, it is also suggested that the use of antioxidants has a protective role in situations of hypogonadism, thereby avoiding or minimizing the effects of sphincter dysfunction arising from oxidative stress.

Considering the trend of progressively wider survival, world populace tends to increasingly get older, encouraging large population studies to prove possible clinical benefits of antioxidants as a protective management against aging and its related co-morbidities known to accelerate free radicals correlated degenerative process.

\section{CONCLUSIONS}

Bilateral orchiectomy in rats led to increased levels of oxidative stress, along with increased deposition of collagen fibers and decreased number of muscle fibers in the urinary sphincter complex of rats.

Supplementation with alpha-tocopherol was shown to be effective for decreasing the levels of 8-epi-PGF2 (a marker for oxidative stress) and it avoided increase in the volumetric density of collagen fibers. However, it did not influence the density of muscle fibers after the castration.

\section{CONFLICT OF INTEREST}

None declared.

\section{REFERENCES}

1. Lexell J: Human aging, muscle mass, and fiber type composition. J Gerontol A Biol Sci Med Sci. 1995; 50(Spec No:) 11-6.

2. Nnodim J0: Testosterone mediates satellite cell activation in denervated rat levator ani muscle. Anat Rec. 2001; 263: 19-24. 
3. Holloszy JO, Chen M, Cartee GD, Young JC: Skeletal muscle atrophy in old rats: differential changes in the three fiber types. Mech Ageing Dev. 1991; 60: 199-213.

4. Chevion M, Berenshtein E, Stadtman ER: Human studies related to protein oxidation: protein carbonyl content as a marker of damage. Free Radic Res. 2000; 33(Suppl): S99-108.

5. Dean RT, Fu S, Stocker R, Davies MJ: Biochemistry and pathology of radical-mediated protein oxidation. Biochem J. 1997; 324: 1-18.

6. Grune T, Reinheckel T, Davies KJ: Degradation of oxidized proteins in mammalian cells. FASEB J. 1997; 11: 526-34.

7. Fillmann HS, Llessuy S, Marroni CA, Fillmann LS, Marroni NP: Diabetes mellitus and anal sphincter pressures: an experimental model in rats. Dis Colon Rectum. 2007; 50: 517-22.

8. Dolber PC, Spach MS: Conventional and confocal fluorescence microscopy of collagen fibers in the heart. J Histochem Cytochem. 1993; 41: 465-9.

9. Mandarim-de-Lacerda CA: Stereological tools in biomedical research. An Acad Bras Cienc. 2003; 75: 469-86. Erratum in: An Acad Bras Cienc. 2007; 79: 51.

10. Hammerer $\mathrm{P}$, Michl U, Meyer-Moldenhauer WH, Huland $\mathrm{H}$ : Urethral closure pressure changes with age in men. J Urol. 1996; 156: 1741-3.

11. Blanchet $P$, Yaici el-D, Cayzergues L, Giuliano F, Jardin A, Benoit $G$, et al.: Identification of androgen receptors in the motoneurons of the external urethral sphincter in the spinal cord of female rats. Eur Urol. 2005; 47: 118-24.

12. Strasser $\mathrm{H}$, Tiefenthaler M, Steinlechner M, Eder I, Bartsch G, Konwalinka G: Age dependent apoptosis and loss of rhabdosphincter cells. J Urol. 2000; 164: 1781-5.

13. Rother P, Löffler S, Dorschner W, Reibiger I, Bengs T: Anatomic basis of micturition and urinary continence. Muscle systems in urinary bladder neck during ageing. Surg Radiol Anat. 1996; 18: 173-7.

14. Carlile A, Davies I, Rigby A, Brocklehurst JC: Age changes in the human female urethra: a morphometric study. J Urol. 1988; 139: 532-5.
15. Montilla P, Espejo I, Muñoz MC, Bujalance I, Muñoz-Castañeda JR, Tunez I: Protective effect of red wine on oxidative stress and antioxidant enzyme activities in the brain and kidney induced by feeding high cholesterol in rats. Clin Nutr. 2006; 25: 146-53.

16. Reckelhoff JF, Kanji V, Racusen LC, Schmidt AM, Yan SD, Marrow J, et al.: Vitamin E ameliorates enhanced renal lipid peroxidation and accumulation of F2-isoprostanes in aging kidneys. Am J Physiol. 1998; 274(3 Pt 2): R767-74.

17. Oner-lyidoğan $Y$, Koçak H, Gürdöl F, Koçak T, Erol B: Urine 8-isoprostane F2alpha concentrations in patients with neurogenic bladder due to spinal cord injury. Clin Chim Acta. 2004; 339: 43-7.

18. Keaney JF Jr, Larson MG, Vasan RS, Wilson PW, Lipinska I, Corey $\mathrm{D}$, et al.: Obesity and systemic oxidative stress: clinical correlates of oxidative stress in the Framingham Study. Arterioscler Thromb Vasc Biol. 2003; 23: 434-9.

19. Beckman KB, Ames BN: The free radical theory of aging matures. Physiol Rev. 1998; 78: 547-81.

20. Santana Castro MA, Ferreira U, Glina S, Santana Castro AC, Matheus WE, Reis LO:Testicular components volume density alteration associated to cis-platinum: can antioxidants offer protection?. Actas Urol Esp. 2010; 34: 282-7.

21. Azzi $A$ : The role of alpha-tocopherol in preventing disease. Eur J Nutr. 2004; 43 (Suppl 1): I/18-25.

22. da Silva RC, Reis LO, Lorenzetti F, Palma P, Ortiz V, Dambros M: $\alpha$-Tocopherol supplementation avoids apoptosis in the anal sphincter. Aging Male. 2012; 15: 48-53.

23. Parekh MH, Lobel R, O'Connor LJ, Leggett RE, Levin RM: Protective effect of vitamin $E$ on the response of the rabbit bladder to partial outlet obstruction. J Urol. 2001; 166: 341-6.

24. Kelâmi A: Treatment of morbus Peyronie--how I do it? Twenty years of experience. Int Urol Nephrol. 1991; 23 589-93.

25. Sheweita SA, Tilmisany AM, Al-Sawaf $\mathrm{H}$ : Mechanisms of male infertility: role of antioxidants. Curr Drug Metab. 2005; 6: 495-501.

\section{Correspondence address} Dr. Miriam Dambros Rua Leandro Dupret, 364 / 92 Sao Paulo, SP, 04025-011, Brazil Fax: + 5511 5546-4086 E-mail: miriamdambros@yahoo.com.br 